\title{
What contributes to wellbeing gains - proficiency or duration of meditation related practices?
}

\author{
Ajay Kumar Nair · John P. John · Seema Mehrotra • Bindu M. Kutty
}

\begin{abstract}
Several studies have shown physical and mental health benefits associated with different schools of meditation. However, reviews have recommended interpretation of study outcomes in the context of school specific traditional practices. In the literature, practice proficiency is often conflated with hours or years of meditation practice and it is difficult to attribute wellbeing gains directly to the proficiency of practice. We carried out two studies to examine wellbeing, practice proficiency, and duration of practice amongst Brahma Kumaris Rajayoga (BKRY) practitioners from India. In Study 1, we surveyed participants ( $n=1009)$ to record the socio-demographics, spiritual lifestyle components, and wellbeing enhancement attributed to their spiritual practice. We developed new measures for evaluating proficiency of BKRY practice and for assessment of progress in wellbeing attributed to BKRY practice. Both measures had high internal consistency scores (alphas 0.95, 0.93). Block-wise hierarchical linear regression analysis showed that after accounting for demographic variables, BKRY practice proficiency strongly predicted progress in wellbeing, explaining over $51.6 \%$ of the total variance. In Study 2, we took three well-matched groups $(n=86)$ that were distinct on the basis of duration of practice (long term, short term and zero term). We examined wellbeing differences in these three groups and the extent of correlation of wellbeing with practice proficiency, progress in wellbeing and duration of practice. We conclude that meditation practice does improve wellbeing and that proficiency of practice is better correlated with most aspects of wellbeing than duration of practice but there are a few aspects of wellbeing that increase with sustained practice over a long time. We recommend that studies involving other schools of spiritual/religious practice incorporate tradition-specific proficiency assessment (instead of using years of practice as a proxy) and also use the Progress in Wellbeing scale for assessing practiceaided improvements in wellbeing.
\end{abstract}

Keywords: spirituality, wellbeing, meditation, Brahma Kumaris, Rajayoga

\section{Introduction}

Spiritual, religious and meditative practices are associated with enhanced wellbeing (Koenig, 2012; Sedlmeier et al., 2012; Sharma, 2006) but several methodological concerns have been raised regarding the extant studies (Goyal et al., 2014; Sedlmeier et al., 2012). Suggestions to address these methodological concerns are being formulated (Davidson \& Kaszniak, 2015; Lutz, Jha, Dunne, \& Saron, 2015) with the note that while there has been progress, research in this domain is still in its early stages (Awasthi, 2013; Davidson \& Kaszniak, 2015).

Meditation expertise, proficiency and duration of practice are often used as synonymous terms (Brefczynski-Lewis, Lutz, Schaefer, Levinson, \& Davidson, 2007; Kaliman et al., 2014) but there is a need for a more nuanced approach. Since different schools of thought differ in terms 
of techniques and goals, as well as underlying belief systems (Dahl, Lutz, \& Davidson, 2015; Sedlmeier et al., 2012), there is a need to study the unique context of a given practice while interpreting any outcome (Lutz et al., 2015; Thomas \& Cohen, 2014). While there have been attempts to connect practice proficiency and better health outcomes (Wiist, Sullivan, St George, \& Wayment, 2012), we have not found studies that examined the linkage between practice proficiency and wellbeing.

In this paper, we use the term "school of thought" as an umbrella term for all categories of religious, spiritual and meditative traditions. "Practice proficiency" denotes proficiency of an individual in the context of beliefs, practices and techniques that may be considered an integral part of a particular school of thought. The term "practitioner" refers to an individual who is actively engaged in the beliefs and practices of any one school of thought. We use the term "wellbeing" in a broad sense such that it denotes a good quality of life across several dimensions, including subjective wellbeing (high positive affect, low negative affect, high satisfaction with life), psychological wellbeing (self-acceptance, mastery and competence, positive relations and engagement and growth), meaning in life (framework for looking at life and sense of fulfilment), and quality of life (in the context of spiritual, religious and personal beliefs). "Progress in wellbeing" and "wellbeing gains" refer to a subjective sense of improvement (or deterioration) in wellbeing parameters that a practitioner might experience after initiation of practice and attributes to the practice. "Prior religiosity" refers to regularity of religious practice before becoming a practitioner. "High religiosity" implies daily or regular prayers (others are categorized as "low religiosity"). We use "prior religiosity" as a shorthand for propensity for regular practice, rather than degree of belief in a particular creed. We will use these terms in the context of one school of thought (the Brahma Kumaris) and then consider how this might lead to broader applications.

The Brahma Kumaris (BK) is an international socio-spiritual organization that offers a variety of free self-development courses based on a philosophy of self-mastery termed as Rajayoga (RY) that is distinct from, and unrelated to, Rajayoga as commonly taught in the tradition of the sage Patanjali (Brahma Kumaris, 2018). BKRY teaches four subjects: knowledge (core tenets of the BKRY philosophy that provide a spiritual framework for looking at life), meditation (also referred to as "yoga" within the group; there are many different meditation techniques used in RY including aspects of concentration, mindfulness, compassion, visualization, directed thinking; all these meditation techniques are based on knowledge), inculcation of virtues (visible through behaviour on the basis of knowledge and meditation), and service to humanity (on the basis of the first three subjects) (Brahma Kumaris, 2018; Ramsay, Manderson, \& Smith, 2010). BKRY also provides spiritual lifestyle guidelines (diet, celibacy, brief meditative breaks during the day, volunteering for service activities etc.) and spiritual practice recommendations (early morning meditation at 4 a.m. or earlier, daily classes at a meditation centre, meditation before and after class) intended to foster self-development and wellbeing outcomes (Ramsay et al., 2010). The Spiritual Applications Research Centre (SpARC) is a BK-affiliated wing dedicated to facilitate creation of methods for selfdevelopment (SpARC, 2018). We wanted to know how BKRY practitioners, given their intense focus on self-development, perceived progress in different aspects of wellbeing (as compared to pre-BKRY days). We also wanted to examine what factors would predict progress in wellbeing. Further, we wanted to compare BKRY practitioners with well-matched non-practitioners, using standard wellbeing measures.

Previous studies on BKRY practitioners have reported an increase in positive thinking and happiness in life (Ramesh, Sathian, Sinu, \& Kiranmai, 2013), reduction in middle latency 
auditory evoked potentials during meditation (Telles \& Naveen, 2004) and improvement in respiratory functions, diastolic blood pressure and lipid profile (Mandape, Bharshankar, \& Phatak, 2015; Vyas \& Dikshit, 2002). An early study on the effect on autonomic changes was inconclusive, mentioning both sympathetic and parasympathetic activations (Telles \& Desiraju, 1993), while a more recent study showed a parasympathetic dominance in BKRY practitioners with more than 5 years of experience (Bharshankar, Mandape, Phatak, \& Bharshankar, 2015). The Mount Abu Open Heart Trial found regression of coronary atherosclerosis in participants who adhered to a healthy lifestyle - a combination of diet, exercise and stress management through BKRY (Gupta et al., 2011). A neuroimaging study found that BKRY practice (between 10 and 22 years) was correlated with neuroplastic changes in brain networks (Panda, Bharath, Upadhyay, \& Mangalore, 2016). A recent EEG study demonstrated state-trait interactions in BKRY practitioners - those with long-term practice (minimum of 10 years) could quickly shift between rest and meditation states as indexed by EEG power changes, whereas novices took more time and the control subjects were unable to achieve any state changes (Nair, Sasidharan, John, Mehrotra, \& Kutty, 2017). Interventional studies using BKRY have shown relief in chronic tension headaches and reduction in plasma cortisol levels in those suffering from headaches for over 5 years (Kiran, Behari, Venugopal, Vivekanandhan, \& Pandey, 2005), reduced neurotic symptoms and increase in hope and happiness (Misra, Gupta, Alreja, \& Prakash, 2013).

We carried out two studies to examine the connection between wellbeing and proficiency. Study 1 surveyed BKRY practitioners to evaluate proficiency and progress in wellbeing attributed to RY practice. We hypothesized that spiritual lifestyle components (regularity of attending spiritual classes and early morning meditation, hours of daily meditation and years of BKRY practice) would predict proficiency, and that proficiency in turn would be a better predictor of progress in wellbeing than years of practice. In Study 2, we examined wellbeing using standard measures in three well-matched groups of those with long-term practice (LTP), short-term practice (STP) and a control group (zero-term practice or ZTP). Our hypothesis was that BKRY practitioners (LTP and STP) would report enhanced wellbeing as compared to ZTP, and that these would be correlated with proficiency of practice. We further hypothesized that LTP would show additional wellbeing enhancements over STP, attributable to their longerterm practice.

\section{Study 1: Proficiency and progress in wellbeing in BKRY practitioners}

The purpose of Study 1 was to examine: a) BKRY practice proficiency and b) progress in wellbeing in a large sample and to examine possible predictors for each. Both these measures are novel and thus this study was exploratory in nature. These two measures are based on BKRY concepts and were developed with inputs from expert practitioners. In this study, we did not have the opportunity to use other commonly used wellbeing measures.

\subsection{Method}

\subsubsection{Data collection}

All survey participants were BKRY practitioners who gave written informed consent and submitted the completed bilingual (English-Hindi or English-Kannada) survey form (called "Rajayoga Practice Checker"). The participants were given the option to withhold their name and contact details if they preferred to stay anonymous.

The survey was administered during different meetings and retreats held in different parts of India - Abu Road (BK headquarters) Bangalore, Coimbatore, Delhi and Chennai. The only 
criteria for participation were the ability to read and be fluent in English, Hindi or Kannada, and consistent (self-reported) meditation experience of at least 6 months. Data collection during the various meetings and retreats ensured that only serious meditators participated in the study. Two of the small retreats comprised dedicated (full-time) BKRY practitioners, while others consisted of a general membership. The meetings focused on both spiritual research (reviewing spiritual material and preparing testable self-development projects) and selfdevelopment, while the retreats focused on experiential aspects.

Prior to the data collection sessions, the need for the survey was highlighted. Participants were given an opportunity for reflection on their own spiritual journey as they took up BKRY practice, and introspection on their strengths and weaknesses in order to rate themselves on the various scales. Detailed explanations with examples were provided to enable the practitioners to carry out the self-rating. Additional clarifications were provided when requested. Honesty and accuracy in filling in the forms were requested and confidentiality was assured, with the commitment that only statistical data would be used for research and development. Since the survey was specifically directed at BKRY practitioners, the questions contained terms that are commonly used within this school of thought. Apart from questions pertaining to sociodemographics and spiritual lifestyle, a key feature of the survey was the self-assessment of 25 core practice components (BKRY practice proficiency scale) covering the four subjects of BKRY. This section was adapted from an unpublished SpARC project that documented the milestones on the journey from novice to mastery. Another important feature was the inclusion of selfassessment of improvement (or deterioration) in several wellbeing parameters (Progress in Wellbeing scale) that the participants attributed to the practice of BKRY.

\subsubsection{Novel measures and data analysis}

Each school of thought has its own philosophy and set of guidelines for practice that enable optimal progress. The existing literature routinely uses years of practice as a shorthand for degree of practitioner expertise. However, it is possible that a short duration of deliberate practice can lead to proficiency levels that may not be achieved with long durations of casual practice. Thus, there is a need for developing practice proficiency measures for each school of thought that can aid in assessing the progress made by the practitioner. The BKRY practice proficiency scale was developed to fulfil this need. The terminology used in the scale is specific to BKRY and is well understood by the practitioners.

The BKRY practice proficiency scale had 25 items $^{1}$ in total, divided into four subscales for measuring each of the four subjects of BKRY. The maximum possible score was 100 . The subscale for "Clarity of Knowledge" had seven items that were scored as follows: Perfect clarity = 4; Very clear = 3; Some clarity $=2 ;$ Not sure $=1 ;$ No idea $=0$. The subscales "Experience of Yoga (Meditation)," "Spiritual Lifestyle" and "Serving the World" had six items each that were scored as follows: Constant experience $=4$; Good experience $=3$; Some experience $=2$; Trying $=1$; No experience $=0$. The term "constant experience" in BKRY refers to the state of embodying or being in that state of experience and therefore is the highest extent of experience possible.

The overall scale and each of the subscales had high internal consistency scores. Cronbach's alphas (and McDonald's omegas with confidence intervals) were 0.94 [0.931 (0.919-0.94)] for “Clarity of Knowledge," 0.87 [0.866(0.85-0.881)] for “Experience of Yoga," 0.85 [0.857(0.839-

\footnotetext{
${ }^{1}$ These items are very specific to the BKRY tradition (for example: concepts such as "tree" and "ladder") and are therefore omitted from the text for clarity and succinctness. The questionnaire can be provided on request.
} 
0.873)] for "Spiritual Lifestyle," 0.88 [0.882(0.867-0.896)] for "Serving the World" and 0.95 [0.948(0.935-0.96)] for the overall proficiency scale.

Several longitudinal studies have reported wellbeing gains in meditators by using a prepost design across a meditation retreat, typically involving novice practitioners. However, this misses out data from the vast majority of experienced practitioners. Further, intense practice of any school of thought can involve major lifestyle changes, leading to issues in adaptation for both the practitioners and those who come in contact with them. Thus, initially, the practitioners may encounter some deterioration in relationships or personal happiness levels (due to heightened awareness of some personal limitations), while in the long run, most practitioners are likely to experience increased wellbeing across all domains. To test these ideas, we developed the Progress in Wellbeing scale to enable the practitioner to rate the extent of change across multiple dimensions of wellbeing (Table 1 below) after commencement of RY practice and attributable to RY practice. Thus, for carrying out the self-assessment of progress in wellbeing (or lack thereof), the participants had to compare their current state of wellbeing to their baseline state just prior to enrolling in BKRY. We did not provide explicit criteria for rating progress across these dimensions, however, BKRY recommends daily journaling (called a progress "chart" - this is flexible and can take many different formats), and so most participants are quite used to evaluating their progress on a regular basis.

The Progress in Wellbeing scale had eight items for checking the participants' sense of "Overall improvement due to Rajayoga" in various aspects of wellbeing (Table 1). The items were scored as follows: Excellent progress $=5$; Very good progress $=4 ;$ Moderate progress $=3 ;$ No change $=2$; Worse in general $=1$; Worse due to Rajayoga $=0$. The scale had an alpha of 0.93 and omega of 0.933(0.923-0.948).

After computing Proficiency and Progress in Wellbeing scores, hierarchical linear regression was carried out to account for demographic variables (age, gender, education, monthly family income, prior religiosity and commitment level) as a block before examining the effect of practice variables on BKRY proficiency. We included prior religiosity (high or low), as it might have a bearing on practice proficiency, and we included commitment level as a binary variable (full-time commitment to BKRY or not), as it could influence depth and duration of practice. Practitioners with full-time commitment are officially designated as "dedicated" or "surrendered" by the BK organization. We then analyzed the effect of BKRY proficiency on progress in wellbeing after accounting for the demographic variables (as a block).

\subsection{Results of Study 1}

A total of 1,500 forms were distributed for Study 1. Completed survey forms of 1,009 respondents (67.2\%) were analyzed. Both genders were well represented (49.2\% female). The average age was 45 years (range 15-83, $S D=14.9$ years). Almost half were married (49.5\%). Most were from a Hindu background (97.5\%) but there were some respondents from Jain, Muslim, Sikh, Buddhist, Christian or atheistic backgrounds. About half had high religiosity $(52.5 \%$, daily or regular prayers) prior to practice of BKRY. The majority were college educated (64.3\%) and most had a middle-class family income (76.1\%). Income earners formed $41.3 \%$ of the group. The non-income earners included dedicated practitioners, householders, students, retired and unemployed categories.

BKRY practice experience ranged from 1 to 57 years (median 12 years). Most respondents meditated for more than 1 hour daily $(76.1 \%)$ and the median lifetime meditation experience was over 7,000 hours. Most respondents regularly attended BKRY spiritual classes (91\%) and 
practiced early morning meditation (80.4\%). More than $90 \%$ of the participants felt that they had experienced substantial progress in wellbeing after starting BKRY practice (Table 1).

Table 1. Progress in wellbeing attributed to BKRY practice $(n=1009$, values in percentage)

\begin{tabular}{lccccccc}
\hline & $\begin{array}{l}\text { Excellent } \\
\text { progress }\end{array}$ & $\begin{array}{l}\text { Very } \\
\text { good } \\
\text { progress }\end{array}$ & Moderate & $\begin{array}{l}\text { No } \\
\text { change }\end{array}$ & $\begin{array}{l}\text { Worse in } \\
\text { general }\end{array}$ & $\begin{array}{l}\text { Worse } \\
\text { due to } \\
\text { Rajayoga }\end{array}$ & $\begin{array}{l}\text { Not } \\
\text { filled }\end{array}$ \\
\hline Happiness & 29.0 & 51.7 & 16.3 & 0.9 & 0.1 & 0.4 & 1.6 \\
Peace & 27.4 & 53.0 & 16.8 & 1.1 & 0.2 & 0.1 & 1.4 \\
Harmony & 19.6 & 50.3 & 24.5 & 2.2 & 0.2 & 0.1 & 3.1 \\
Values & 21.2 & 48.2 & 23.5 & 1.7 & 0.2 & 0.0 & 5.3 \\
$\begin{array}{l}\text { Self- } \\
\text { Development }\end{array}$ & 23.0 & 51.0 & 22.9 & 0.9 & 0.3 & 0.1 & 1.8 \\
$\begin{array}{l}\text { Work } \\
\text { Effectiveness }\end{array}$ & 22.3 & 48.1 & 24.7 & 1.7 & 0.2 & 0.0 & 3.1 \\
$\begin{array}{l}\text { Spiritual } \\
\text { Growth }\end{array}$ & 21.8 & 50.4 & 23.7 & 1.3 & 0.1 & 0.0 & 2.7 \\
$\begin{array}{l}\text { Quality of } \\
\text { Life }\end{array}$ & 20.4 & 52.1 & 23.0 & 1.2 & 0.2 & 0.0 & 3.1 \\
\hline
\end{tabular}

The RY practice proficiency scores ranged from 22.0 to $100(M=71.53, S D=14.04)$. Hierarchical linear regression indicated that demographic variables (age, gender, education, monthly family income, prior religiosity and commitment status to BKRY) were significant determinants $\left(F_{14,714}\right.$ $=3.53, p<0.001$ ) and explained $4.6 \%$ of the variance (adjusted R-squared). Over and above the demographic variables, years of RY practice, hours of daily meditation, regularity of early morning meditation ( 4 a.m.) and regularity of spiritual study were significant determinants $\left(F_{27}\right.$, $701=12.95, p<0.001$ ) of practice proficiency, explaining $30.7 \%$ of the total variance.

The Progress in Wellbeing scores ranged from 16 to $40(M=31.91, S D=4.78)$. As can be seen in Table 1, more than $95 \%$ of the participants felt that they had made progress (excellent, very good or moderate) in all the wellbeing dimensions, as compared to the pre-BKRY baseline. Hierarchical linear regression indicated that demographic variables were not significant determinants $\left(F_{14,686}=1.30, p=0.2\right)$. Over and above the demographic variables, practice proficiency strongly predicted (Figure 1$)$ progress in wellbeing $\left(F_{15,685}=50.9, p<0.001\right.$ ), explaining $51.68 \%$ of the total variance (adjusted R-squared). Figure 1 below shows the correlations between progress in wellbeing, practice proficiency and years of practice. Progress in wellbeing was strongly correlated with proficiency in BKRY practice ( $r=0.72,95 \%$ CI 0.68 to 0.75 ) and weekly correlated with years of BKRY practice $(r=0.16,95 \%$ CI 0.08 to 0.23$)$. Proficiency was correlated with years of BKRY practice $(r=0.29,95 \% \mathrm{CI} 0.22$ to 0.36$)$. Shaded lines show $95 \%$ confidence intervals. 
Figure 1. Progress in wellbeing as a function of proficiency (top), and years of practice

(bottom left) in BKRY. Proficiency as a function of years of practice (bottom right).
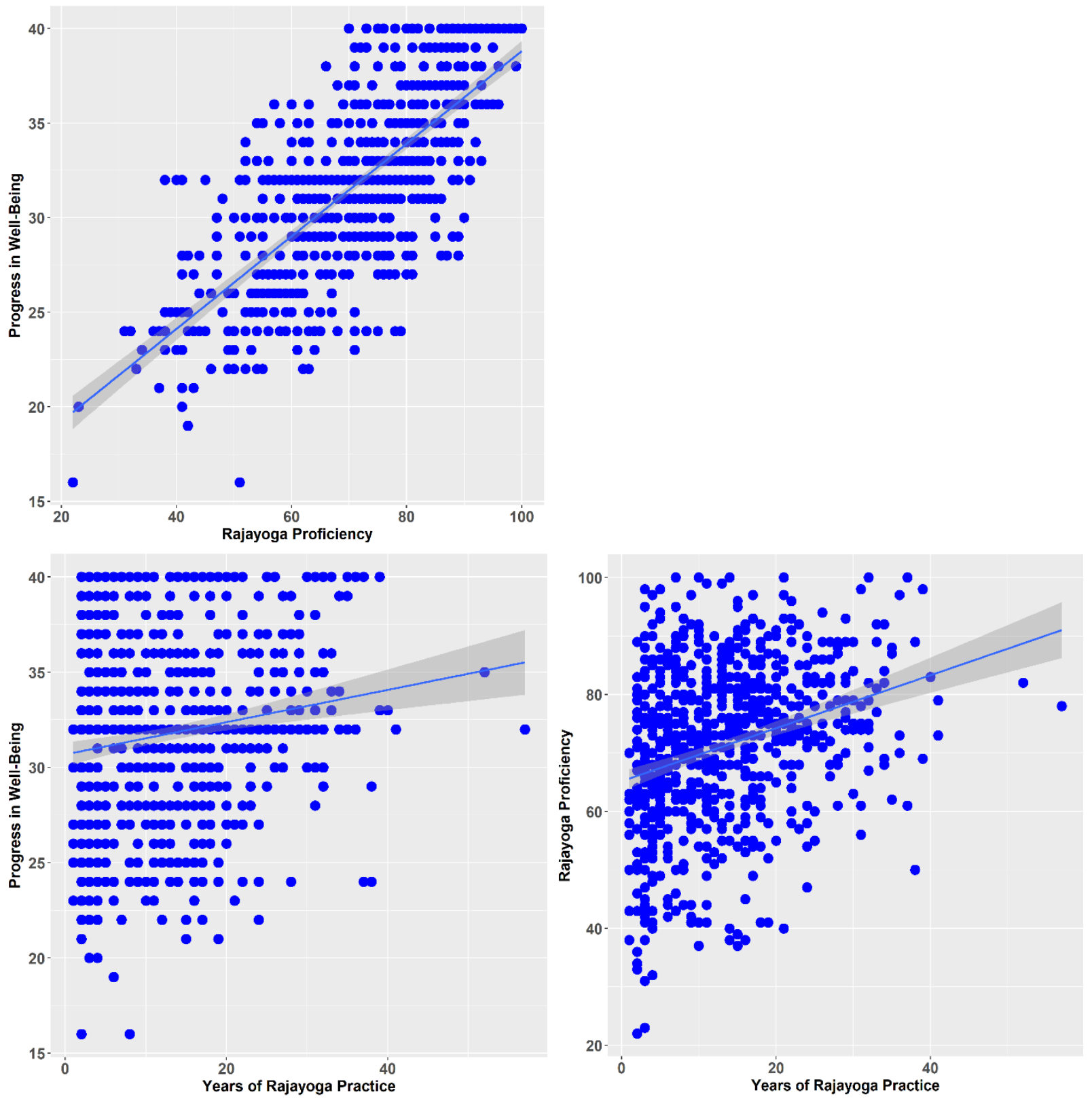

\subsection{Discussion of Study 1}

The results provide evidence to support the hypothesis that the participants experienced improvements in wellbeing due to BKRY practice. While several previous reports have assessed wellbeing in meditators, the present study is the first to specifically query the sense of progress in wellbeing attributed to the practice. Also, as hypothesized, practice proficiency strongly predicted progress in wellbeing.

There have been some attempts to make assessment scales that are specific to other schools of thought. Religious understanding of basic precepts of Buddhism (including the creation of a Buddhist Devoutness Index) was found to predict improvement in health (Wiist et al., 2012). Manocha and colleagues in their study reported that items (such as meditation frequency, 
group meditation, socialising with other practitioners, and substance usage) in the Meditation Lifestyle Survey (MLS) of long-term Sahaja Yoga practitioners predicted the depth of mental silence experienced (Manocha, Black, \& Wilson, 2012). A recent theoretical formulation of a phenomenological matrix of mindfulness-related practices is a welcome development (Lutz et al., 2015), and, as the authors suggested, needs to go through iterations of empirical testing and modification. The present study is the first to link practice proficiency and a corresponding sense of progress in wellbeing attributed to the practice.

The socio-demographics showed that BKs represent all segments of society in terms of age, gender, education, income, profession and marital status. Our study shows that high prior religiosity is not a prerequisite for engaging in or sustaining spiritual practice. Thus, even if the practitioners were not regular in their prayers or other religious/spiritual practices prior to enrolling in BKRY, the majority had a substantial commitment to self-development, as demonstrated by regular attendance of spiritual classes (involving a visit to the local meditation centre and lasting for at least 1 hour), participation in early morning meditation (4 a.m. or earlier) and more than an hour of daily meditation. Taken together, BKs engage in a significant alteration of their personal time and lifestyle choices while progressing on their path of self-development (Ramsay et al., 2010). Since $78.1 \%$ of the sample had more than 5 years of BKRY practice, it is likely that the lifestyle changes in these practitioners have been sustained over a long period of time.

We did not assess wellbeing per se using standard measures in Study 1 but other studies have shown that BKRY practitioners have enhanced happiness in life (Ramesh et al., 2013), as compared to non-meditators, and that long-term BKRY practitioners had fewer neurotic symptoms, and higher hope and happiness as compared to short-term practitioners (Misra et al., 2013). These studies are similar to the bulk of the literature that has examined wellbeing in meditators, as they conflate duration of practice with proficiency of practice. To confirm that these two variables are indeed different, we did separate analyses and found that duration of practice predicts proficiency $(8.4 \%$ of the variance) and progress in wellbeing $(2.5 \%$ of the variance) but this forms a very small contribution compared to the overall contribution of practice proficiency to progress in wellbeing. Thus our study suggests that instead of using years of practice as a proxy for proficiency or expertise in meditation, there is a need to explicitly assess proficiency using measures that are specific to each school of thought.

How might a practitioner achieve high proficiency within a short duration and another achieve only low proficiency even after long-term practice? A number of factors can contribute to this situation. As discussed earlier, proficiency in BKRY requires significant investment in terms of lifestyle adaptations (Ramsay et al., 2010). The proficiency gains are likely to be dependent on how quickly and how much a practitioner is willing to undergo these changes. For some people, the conceptual framework is compelling enough to make large-scale changes in earnest. Others might be more interested in the stress-relieving aspects of meditation and therefore focus only on that aspect. Overall, our findings are in line with the literature that deliberate and focused practice builds higher competence than routine, unfocused practice (Ericsson, 2006).

Meditation practice, and, to a greater extent, absorption, have an influence on meditation depth (Hölzel \& Ott, 2006). In our study, different aspects of meditation depth were part of the assessment of practice proficiency. A study on long-term Sahaja Yoga meditators also showed that experience of mental silence (related to meditation depth) was facilitated by various practices and lifestyle factors (Manocha et al., 2012). 
The BKRY practice proficiency scale and its four subscales had high internal consistency scores. The Progress in Wellbeing scale also had a high internal consistency score and can easily be adapted for use with other schools of meditation or spiritual self-development programs. Our study indicates that a full assessment of practice proficiency is indeed a predictor of progress in wellbeing, as suggested by others (Sedlmeier et al., 2012).

While most practitioners reported progress in wellbeing across all the parameters, there were a few respondents who sensed a deterioration in their wellbeing after they started the practice of BKRY due to extraneous factors $(<1 \%)$ and specifically due to BKRY practice $(<1 \%)$, but the latter did not find that it affected their progress in work effectiveness, spiritual growth or overall quality of life. This deterioration in wellbeing could be due to the difficulties in coping with the challenges of self-change or due to difficulties that come when friends and relatives oppose changes in lifestyle. The results show that BKRY practitioners who adapt to the lifestyle changes experience a significant sense of progress in wellbeing. This is in line with other reports that show that meditation practitioners experience enhanced wellbeing on a number of measures (Manocha et al., 2012; Orme-Johnson \& Dillbeck, 2014).

\section{Study 2: Wellbeing in BKRY practitioners in relation to proficiency and duration}

The purpose of Study 2 was to evaluate wellbeing using standard measures in three distinct groups based on duration of practice (LTP, STP and ZTP) but well matched on socio-economic aspects. We then examined (for LTP and STP), correlation between the different wellbeing results and BKRY practice proficiency, as well as duration of practice. While the Progress in Wellbeing scale indicates progress across a number of dimensions (Table 1), it does not necessarily indicate high wellbeing in any of the dimensions, as it is possible that the baseline was quite low. Therefore, we wanted to assess several standard measures of wellbeing and examine how progress in wellbeing correlates with them. Study 2 participants also took part in an EEG study on the ability to rapidly shift between rest and meditation states within a minute (Nair et al., 2017), which constrained the sample size.

\subsection{Method}

\subsubsection{Participants}

BKRY practitioners (LTP and STP) were enlisted for the study with help and follow-up support of the regional coordinating offices of BKRY centres in Bangalore. LTP had a minimum of 10 years of meditation experience and STP had at least 6 months and at most 2 years of meditation experience. Control participants (ZTP) were recruited from the local community, and, where possible, were non-meditator colleagues of the practitioner participants. This was done to match the socio-economic and work background as much as possible. Care was taken to ensure that none of the participants had had any lifetime exposure to any other form of meditation. Table 2 below lists the socio-demographics of the participants. 
Table 2. Socio-demographics for Study 2 participants

\begin{tabular}{|c|c|c|c|c|}
\hline Demographics & $\operatorname{LTP}(n=36)$ & $\operatorname{STP}(n=25)$ & $\mathrm{ZTP}(n=25)$ & Statistics \\
\hline \multicolumn{5}{|l|}{ Age } \\
\hline $\begin{array}{l}\text { Mean } \\
\text { (Min, Max) }\end{array}$ & $\begin{array}{l}45.06 \\
(31,64)\end{array}$ & $\begin{array}{l}44.28 \\
(27,61)\end{array}$ & $\begin{array}{l}45.04 \\
(27,59)\end{array}$ & $F=0.05, p=0.95$ \\
\hline \multicolumn{5}{|l|}{ Gender } \\
\hline Female & 14 & 11 & 11 & $\chi^{2}=0.22, p=0.89$ \\
\hline Male & 22 & 14 & 14 & \\
\hline \multicolumn{5}{|l|}{ Education } \\
\hline School Level & 8 & 11 & 10 & $\chi^{2}=6.33, p=0.17$ \\
\hline Diploma or Degree & 15 & 11 & 10 & \\
\hline Post Graduate or Above & 13 & 3 & 5 & \\
\hline \multicolumn{5}{|l|}{ Monthly Family Income } \\
\hline High Income & 4 & 3 & 4 & Low cell counts $\$$ \\
\hline Upper Middle Income & 5 & 3 & 5 & \\
\hline Lower Middle Income & 26 & 18 & 16 & \\
\hline Low Income & 1 & 1 & 0 & \\
\hline \multicolumn{5}{|l|}{ Body Mass Index (BMI) } \\
\hline Mean (Min, max) & $24.72(17,34)$ & $25.56(19,39)$ & $26.12(20,34)$ & $F=0.93, p=0.4$ \\
\hline \multicolumn{5}{|l|}{ Religiosity } \\
\hline High & 19 & 16 & 20 & $\chi^{2}=4.81, p=0.3$ \\
\hline Medium & 8 & 4 & 2 & \\
\hline Low & 9 & 5 & 3 & \\
\hline $\begin{array}{l}\text { Meditation Median (Hrs) } \\
\text { (Min, max) }\end{array}$ & $\begin{array}{l}14240 \\
(7300,35040)\end{array}$ & $\begin{array}{l}1095 \\
(255,2190)\end{array}$ & 0 & $t=12.34, p=0.00$ \\
\hline
\end{tabular}

Note: \$Low cell counts prevent accurate statistics, but these values are comparable and differences are not significant.

\subsubsection{Measures}

The following wellbeing measures were used:

1) Positive and Negative Affect Schedule (PANAS) - Revised (Rao \& Mehrotra, 2006; Feldman Barrett \& Russell, 1998; Watson \& Clark, 1988). In the revised form (and adapted to the Indian context), this 26-item scale has two 13-item subscales for measuring positive affect and negative affect and has a 5-point Likert-type scale ranging from "Very slightly or not at all" to "Extremely." The state version was used for this study. It is considered to be the affective component of the subjective wellbeing.

2) Psychological Wellbeing (PWB) (Mehrotra, Tripathi \& Banu, 2013; Ryff, 1989; Ryff \& Keyes, 1995). This is a 20 -item revised version of the original scale, adapted to the 
Indian context. It assesses the trait notion of eudaimonic wellbeing and has four subscales: Self-Acceptance, Mastery and Competence, Positive Relations and Engagement, and Growth. Each subscale uses the same 6-point Likert-type scale ranging from "Strongly Agree" to "Strongly Disagree."

3) Satisfaction with Life Scale (SWLS) (Diener. Emmons, Larson, \& Griffin, 1985). This is a 5-item scale using a cognitive approach to assess one's overall level of satisfaction with life. It has a 7-point Likert-type scale ranging from "Strongly Disagree" to "Strongly Agree." It is considered to be the cognitive component of subjective wellbeing.

4) Life Regard Index (LRI) (Battista \& Almond, 1973; Debats, van der Lubbe, \& Wezeman, 1993). This 28-item scale evaluates the trait concept of meaningful life and has two 14-item subscales assessing Framework and Fulfilment aspects of a meaningful life. It has a 3-point Likert-type scale with options of "Disagree," "No Opinion" and "Agree."

5) WHO Quality of Life - Spiritual Religious or Personal Beliefs (SRPB) (WHOQOL SRPB Group, 2006). This is a 32-item scale with eight subscales with four items each for "Spiritual Connection," "Meaning and Purpose in Life," "Experiences of Awe and Wonder," "Wholeness and Integration," "Spiritual Strength," "Inner Peace," "Hope and Optimism" and "Faith," each having a 5-point Likert-type scale ranging from "Not at all" to "An extreme amount" or "Extremely" or "Completely" for different subscales. It is used to assess how much one's belief system might contribute to quality of life. It is a state scale with a timeframe of "last two weeks."

6) Rajayoga Practice Checker (RPC). This was the same questionnaire used in Study 1. We also made a subset (without the spiritual practice components) for obtaining the socio-demographic details of the ZTP group.

The overall RY proficiency scale (and each of its subscales) and Progress in Wellbeing scale had high internal consistency scores similar to the scores in Study 1. Cronbach's alphas were 0.90 for "Clarity of Knowledge," 0.78 for "Experience of Yoga," 0.85 for "Spiritual Lifestyle," 0.91 for "Serving the World," 0.92 for the overall "Rajayoga Proficiency" scale and 0.89 for the "Progress in Wellbeing" scale. Study 2 evaluated wellbeing using a number of measures considering subjective wellbeing, psychological wellbeing, meaning in life, and contribution of belief to quality of life. All the scales used (and their subscales) showed high internal consistency scores, indicating their reliability and suitability for assessment in this population. While Cronbach's alpha is the most commonly used measure of internal consistency, its use has been criticized with a strong recommendation to instead report McDonald's omega (Dunn, Baguley, \& Brunsden, 2014), along with confidence intervals. Alpha and omega scores were similar in the present study and showed that the scales were reliable and suitable for use. Table 3 below lists the Cronbach's alphas, McDonald's omega and confidence intervals for all the wellbeing measures. 
Table 3. Reliability scores for the wellbeing measures

Wellbeing Measure

Alpha, Omega (CI)

Positive and Negative Affect Schedule

Positive Affect

$0.87,0.87(0.81-0.91)$

Negative Affect

$0.81,0.82(0.75-0.87)$

\section{Psychological Wellbeing}

Overall

$0.86,0.86(0.79-0.90)$

Self-Acceptance

$0.71,0.72(0.50-0.81)$

Mastery and Competence

$0.74,0.75(0.66-0.81)$

Positive Relations

$0.68,0.69(0.57-0.77)$

Engagement and Growth

$0.66,0.70(0.49-0.81)$

\section{Satisfaction with Life Scale}

Overall

$0.76,0.73(0.59-0.80)$

Life Regard Index

Overall

$0.85,0.84(0.75-0.89)$

Framework

$0.72,0.71(0.56-0.80)$

Fulfilment

$0.75,0.74(0.62-0.83)$

Spiritual, Religious and Personal Beliefs

Overall

$0.96,0.96(0.95-0.97)$

Spiritual Connection

$0.87,0.96(0.95-0.97)$

Meaning and Purpose in Life

$0.74,0.75(0.66-0.81)$

Experiences of Awe and Wonder

$0.77,0.77(0.66-0.84)$

Wholeness and Integration

$0.82,0.82(0.75-0.88)$

Spiritual Strength

$0.83,0.83(0.74-0.9)$

Inner Peace

$0.87,0.88(0.82-0.92)$

Hope and Optimism

$0.88,0.88(0.81-0.93)$

Faith

$0.86,0.86(0.79-0.92)$

\subsection{Results of Study 2}

Statistical comparisons (using appropriate methods listed in Table 4 below) revealed that BKRY practitioners (LTP and STP) had significantly enhanced wellbeing as compared to ZTP for almost all the wellbeing measures (Table 4). The exceptions were for subscales on selfacceptance, positive relations, engagement and growth, awe and wonder, and spiritual strength. Further evaluation using the Jonckheere-Terpstra test (which has a directional hypothesis and thus higher power) revealed that all these variables had a significant decreasing trend (i.e., LTP $\geq$ STP $\geq$ ZTP), as expected. Most wellbeing variables were correlated with Rajayoga proficiency and with progress in wellbeing (Table 5 below). Three outcome variables were correlated with meditation duration: engagement, wholeness and integration, and spiritual strength. 
Table 4a. Wellbeing measures (M and SD) and group differences

\begin{tabular}{|c|c|c|c|c|c|c|c|}
\hline $\begin{array}{l}\text { Wellbeing } \\
\text { measures }\end{array}$ & LTP $(n=36)$ & STP $(n=25)$ & ZTP $(n=25)$ & Group Results & $\begin{array}{l}\text { LTP vs } \\
\text { ZTP }\end{array}$ & $\begin{array}{l}\text { STP vs } \\
\text { ZTP }\end{array}$ & $\begin{array}{l}\text { LTP vs } \\
\text { STP }\end{array}$ \\
\hline $\begin{array}{l}\text { Positive } \\
\text { Affect }\end{array}$ & $\begin{array}{l}47.69 \\
(7.65)\end{array}$ & $\begin{array}{l}47.08 \\
(8.64)\end{array}$ & $\begin{array}{l}40.96 \\
(9.83)\end{array}$ & $\begin{array}{l}F=5.06, \\
p=0.008\end{array}$ & $p=0.009$ & $p=0.037$ & $p=0.959$ \\
\hline $\begin{array}{l}\text { Negative } \\
\text { Affect }\end{array}$ & $\begin{array}{l}20.56 \\
(6.52)\end{array}$ & $\begin{array}{l}21.44 \\
(5.32)\end{array}$ & $\begin{array}{l}28.52 \\
(7.63)\end{array}$ & $\begin{array}{l}H=17.66 \\
p=0\end{array}$ & $\begin{array}{l}\text { TRUE, } \\
\text { JT=1713 }\end{array}$ & TRUE & FALSE \\
\hline Overall PWB & $\begin{array}{l}101.33 \\
(12.8)\end{array}$ & $\begin{array}{l}100.24 \\
(13.22)\end{array}$ & $\begin{array}{l}88.24 \\
(16.4)\end{array}$ & $\begin{array}{l}\mathrm{H}=10.93 \\
p=0.004\end{array}$ & TRUE & TRUE & FALSE \\
\hline $\begin{array}{l}\text { Self- } \\
\text { Acceptance }\end{array}$ & $\begin{array}{l}22.22 \\
(2.26)\end{array}$ & $\begin{array}{l}22.28 \\
(3.12)\end{array}$ & $\begin{array}{l}19.88 \\
(4.12)\end{array}$ & $\begin{array}{l}F_{t}=3.17 \\
p=0.058\end{array}$ & $J T=992^{*}$ & & \\
\hline $\begin{array}{l}\text { Mastery and } \\
\text { Competence }\end{array}$ & $\begin{array}{l}26.86 \\
(6.86)\end{array}$ & $\begin{array}{l}26.92 \\
(5.84)\end{array}$ & $\begin{array}{l}21.76 \\
(7.83)\end{array}$ & $\begin{array}{l}H=8.13 \\
p=0.017\end{array}$ & $\begin{array}{l}\text { TRUE } \\
\mathrm{JT}=\mathbf{8 9 7}^{* *}\end{array}$ & FALSE & FALSE \\
\hline $\begin{array}{l}\text { Positive } \\
\text { Relations }\end{array}$ & $\begin{array}{l}23.86 \\
(4.85)\end{array}$ & $\begin{array}{l}23.44 \\
(5.31)\end{array}$ & $\begin{array}{l}20.44 \\
(5.98)\end{array}$ & $\begin{array}{l}H=5.42 \\
p=0.067\end{array}$ & $J T=953.5^{*}$ & & \\
\hline $\begin{array}{l}\text { Engagement } \\
\text { and Growth }\end{array}$ & $\begin{array}{l}28.39 \\
(2.16)\end{array}$ & $\begin{array}{l}27.6 \\
(2.33)\end{array}$ & $\begin{array}{l}26.14 \\
(4.41)\end{array}$ & $\begin{array}{l}H=3.99 \\
p=0.136\end{array}$ & $J T=953^{*}$ & & \\
\hline $\begin{array}{l}\text { Life } \\
\text { Satisfaction }\end{array}$ & $\begin{array}{l}26.03 \\
(6.54)\end{array}$ & $\begin{array}{l}27.04 \\
(4.86)\end{array}$ & $\begin{array}{l}23.28 \\
(5.91)\end{array}$ & $\begin{array}{l}H=6.16 \\
p=0.046\end{array}$ & $J T=966^{*}$ & & \\
\hline Overall LRI & $\begin{array}{l}76.69 \\
(4.87)\end{array}$ & $\begin{array}{l}75.4 \\
(6.11)\end{array}$ & $\begin{array}{l}67.36 \\
(9.21)\end{array}$ & $\begin{array}{l}F_{t}=7.65, \\
\xi=0.66\end{array}$ & $\xi=0.75$ & $\xi=0.63$ & $\xi=0.10$ \\
\hline Framework & $\begin{array}{l}39.42 \\
(2.06)\end{array}$ & $\begin{array}{l}38.84 \\
(2.81)\end{array}$ & $\begin{array}{l}34.56 \\
(4.49)\end{array}$ & $\begin{array}{l}F_{t}=7.25, \\
\xi=0.86\end{array}$ & $\xi=0.73$ & $\xi=0.72$ & $\xi=0.07$ \\
\hline Fulfilment & $\begin{array}{l}37.28 \\
(3.62)\end{array}$ & $\begin{array}{l}36.56 \\
(4.35)\end{array}$ & $\begin{array}{l}32.8 \\
(5.05)\end{array}$ & $\begin{array}{l}H=13.74 \\
p=0.001\end{array}$ & $\begin{array}{l}\text { TRUE } \\
J T=794^{* * *}\end{array}$ & TRUE & FALSE \\
\hline Overall SRPB & $\begin{array}{l}134.44 \\
(13.5)\end{array}$ & $\begin{array}{l}131.48 \\
(15.28)\end{array}$ & $\begin{array}{l}108.44 \\
(22.6)\end{array}$ & $\begin{array}{l}F_{t}=9.08, \\
\xi=0.7\end{array}$ & $\xi=0.81$ & $\xi=0.71$ & $\xi=0.08$ \\
\hline $\begin{array}{l}\text { Spiritual } \\
\text { Connection }\end{array}$ & $\begin{array}{l}17.14 \\
(1.96)\end{array}$ & $\begin{array}{l}16.28 \\
(3.18)\end{array}$ & $\begin{array}{l}12.96 \\
(3.56)\end{array}$ & $\begin{array}{l}F_{t}=9.78, \\
\xi=0.65\end{array}$ & $\xi=0.93$ & $\xi=0.70$ & $\xi=0.07$ \\
\hline $\begin{array}{l}\text { Meaning and } \\
\text { Purpose }\end{array}$ & $\begin{array}{l}16.94 \\
(2.19)\end{array}$ & $\begin{array}{l}16.68 \\
(2.72)\end{array}$ & $\begin{array}{l}14.04 \\
(2.56)\end{array}$ & $H=17.65, p=0$ & $\begin{array}{l}\text { TRUE, } \\
J T=770^{* * *}\end{array}$ & TRUE & FALSE \\
\hline $\begin{array}{l}\text { Awe and } \\
\text { Wonder }\end{array}$ & $\begin{array}{l}16.17 \\
(2.31)\end{array}$ & $\begin{array}{l}15.84 \\
(2.59)\end{array}$ & $\begin{array}{l}13.44 \\
(3.57)\end{array}$ & $\begin{array}{l}F_{t}=2, \\
p=0.156\end{array}$ & $J T=883^{* *}$ & & \\
\hline $\begin{array}{l}\text { Wholeness } \\
\text { and } \\
\text { Integration }\end{array}$ & $\begin{array}{l}16.22 \\
(2.13)\end{array}$ & $\begin{array}{l}15.96 \\
(2.24)\end{array}$ & $\begin{array}{l}13.2 \\
(4.05)\end{array}$ & $\begin{array}{l}F_{t}=4.86, \\
\xi=0.61\end{array}$ & $\xi=0.69$ & $\xi=0.58$ & $\xi=0.11$ \\
\hline $\begin{array}{l}\text { Spiritual } \\
\text { Strength }\end{array}$ & $\begin{array}{l}17.53 \\
(1.86)\end{array}$ & $\begin{array}{l}16.84 \\
(2.03)\end{array}$ & $\begin{array}{l}14.24 \\
(4.62)\end{array}$ & $\begin{array}{l}F_{t}=3.16 \\
p=0.059\end{array}$ & $J T=839^{* *}$ & & \\
\hline
\end{tabular}


Table $4 b$. Wellbeing Measures (M and SD) and group differences

\begin{tabular}{|c|c|c|c|c|c|c|c|}
\hline $\begin{array}{l}\text { Wellbeing } \\
\text { measures }\end{array}$ & $\begin{array}{l}\text { LTP } \\
(n=36)\end{array}$ & $\begin{array}{l}\text { STP } \\
(n=25)\end{array}$ & $\begin{array}{l}\text { ZTP } \\
(n=25)\end{array}$ & $\begin{array}{l}\text { Group } \\
\text { Results }\end{array}$ & $\begin{array}{l}\text { LTP vs } \\
\text { ZTP }\end{array}$ & $\begin{array}{l}\text { STP vs } \\
\text { ZTP }\end{array}$ & $\begin{array}{l}\text { LTP vs } \\
\text { STP }\end{array}$ \\
\hline Inner Peace & $\begin{array}{l}16.39 \\
(2.1)\end{array}$ & $\begin{array}{l}16.08 \\
(1.89)\end{array}$ & $\begin{array}{l}12.48 \\
(3.62)\end{array}$ & $\begin{array}{l}F_{t}=10.89, \\
\xi=0.87\end{array}$ & $\xi=0.76$ & $\xi=0.91$ & $\xi=0.11$ \\
\hline $\begin{array}{l}\text { Hope and } \\
\text { Optimism }\end{array}$ & $\begin{array}{l}16.58 \\
(2.45)\end{array}$ & $\begin{array}{l}16.88 \\
(2.05)\end{array}$ & $\begin{array}{l}13.32 \\
(4.07)\end{array}$ & $\begin{array}{l}F_{t}=4.95, \\
\xi=0.61\end{array}$ & $\xi=0.64$ & $\xi=0.61$ & $\xi=0.08$ \\
\hline Faith & $\begin{array}{l}17.47 \\
(2.08)\end{array}$ & $\begin{array}{l}16.92 \\
(2.4)\end{array}$ & $\begin{array}{l}14.76 \\
(3.72)\end{array}$ & $\begin{array}{l}F_{t}=3.7, \\
\xi=0.5\end{array}$ & $\xi=0.55$ & $\xi=0.46$ & $\xi=0.11$ \\
\hline
\end{tabular}

F: One-way ANOVA followed by Tukey's HSD post-hoc test. $H$ : Kruskal-Wallis rank sum test.

$J T:$ Jonckheere-Terpstra trend test. " $\mathrm{p}<0.05$, decreasing LTP $\geq \mathrm{STP} \geq \mathrm{ZTP}$

$F_{t}$ : Robust one-way ANOVA using trimmed data followed by $\xi$ : Robust explanatory effect size calculated for robust one-way ANOVA and pairwise post hoc

Note: Values in bold are statistically significant.

Table 5. Correlations between wellbeing measures and proficiency, progress in wellbeing and practice duration

\begin{tabular}{|c|c|c|c|}
\hline Measure & Practice Proficiency & $\begin{array}{l}\text { Progress in } \\
\text { Wellbeing }\end{array}$ & $\begin{array}{l}\text { Meditation } \\
\text { Duration }\end{array}$ \\
\hline \multicolumn{4}{|c|}{ Positive and Negative Affect Schedule } \\
\hline Positive Affect (PA) & $r=0.36, p=0.005$ & $r=0.4, p=0.001$ & n.s. \\
\hline Negative Affect (NA) & $\operatorname{tau}=-0.16, p=0.04$ & n.s. & n.s. \\
\hline \multicolumn{4}{|c|}{ Psychological Wellbeing Scale (PWB) } \\
\hline PWB (Overall) & $r=0.28, p=0.032$ & $r=0.31, p=0.015$ & n.s. \\
\hline Self-Acceptance (SA) & tau $=0.18, p=0.03$ & n.s. & n.s. \\
\hline Mastery (MC) & $\operatorname{tau}=0.18, p=0.026$ & $\operatorname{tau}=0.17, p=0.034$ & n.s. \\
\hline Positive Relations (PR) & $\operatorname{tau}=0.2, p=0.015$ & $\operatorname{tau}=0.24, p=0.005$ & n.s. \\
\hline Engagement (EG) & n.s. & $\operatorname{tau}=0.19, p=0.026$ & $\operatorname{tau}=0.19, p=0.02$ \\
\hline \multicolumn{4}{|c|}{ Satisfaction with Life Scale (SWLS) } \\
\hline Life Satisfaction (LS) & $\operatorname{tau}=0.2, p=0.015$ & n.s. & n.s. \\
\hline \multicolumn{4}{|l|}{ Life Regard Index (LRI) } \\
\hline LRI Total & n.s. & $\operatorname{tau}=0.17, p=0.034$ & n.s. \\
\hline Framework (FR) & n.s. & n.s. & n.s. \\
\hline Fulfilment (FU) & $\operatorname{tau}=0.2, p=0.017$ & $\operatorname{tau}=0.19, p=0.021$ & n.s. \\
\hline \multicolumn{4}{|c|}{ Spiritual, Religious and Personal Beliefs (SRPB) } \\
\hline SRPB (Overall) & $r=0.45, p=0$ & $r=0.41, p=0.001$ & n.s. \\
\hline Connection & $\operatorname{tau}=0.21, p=0.015$ & $\operatorname{tau}=0.28, p=0.002$ & n.s. \\
\hline Meaning & n.s. & $\operatorname{tau}=0.18, p=0.03$ & n.s. \\
\hline Awe & $\operatorname{tau}=0.22, p=0.01$ & n.s. & n.s. \\
\hline Wholeness & $\operatorname{tau}=0.39, p=0$ & $\operatorname{tau}=0.33, p=0$ & $\operatorname{tau}=0.19, p=0.02$ \\
\hline Strength & $\operatorname{tau}=0.32, p=0$ & $\operatorname{tau}=0.24, p=0.006$ & $\operatorname{tau}=0.22, p=0.01$ \\
\hline Peace & $\operatorname{tau}=0.35, p=0$ & $\operatorname{tau}=0.27, p=0.003$ & n.s. \\
\hline Hope & $\operatorname{tau}=0.17, p=0.033$ & n.s. & n.s. \\
\hline Faith & $\operatorname{tau}=0.29, p=0.001$ & $\operatorname{tau}=0.31, p=0.001$ & n.s. \\
\hline
\end{tabular}

$r$ : Karl Pearson's product-moment correlation coefficient. tau: Kendall's rank correlation coefficient. n.s.: not significant 


\subsection{Discussion of Study 2}

The results of Study 2 provide evidence to support the hypothesis that the BKRY participants (LTP and STP) had higher wellbeing than controls across a number of measures: subjective wellbeing, psychological wellbeing, meaning in life and contribution of belief into quality of life. We discuss these findings below. As hypothesized, practice proficiency and progress in wellbeing were well correlated with most measures of wellbeing. Surprisingly, and contrary to our hypothesis, LTP did not show more enhanced wellbeing than STP in any measure, and although there were significant trends of higher wellbeing in LTP as compared to STP, there were no overall group differences. Duration of practice was correlated with only three subscales.

\subsubsection{Subjective wellbeing}

The Subjective Wellbeing (SWB) scores for the ZTP were similar (i.e., no significant differences for Positive Affect (PA), Negative Affect (NA) or Life Satisfaction (LS)) to that found in the literature (Agrawal et al., 2011). Agrawal and colleagues (2011) had evaluated SWB and its socio-demographic correlates in a large sample $(n=1099)$ from an urban Bangalore population. Since our sample is also from Bangalore, the scores for ZTP in the present study replicate the findings in the literature.

LTP and STP both showed significantly enhanced PA and reduced NA as compared to ZTP, showing that Rajayoga practice is associated with improved affect balance. This is in agreement with recent meta-analyses (Goyal et al., 2014; Sedlmeier et al., 2012) which show decreased NA in meditators, and with a previous study of Rajayoga practitioners that found increased happiness scores in RY meditators as compared to non-meditators (Ramesh et al., 2013). There were no significant differences for PA between LTP and STP, which is in contrast to a previous study which showed that the long-term Rajayoga group scored higher on hope and happiness as compared to the short-term group (Misra et al., 2013). Since Misra and colleagues (2013) had used Lyubomirsky and Lepper's (1999) scale, it is difficult to directly comment on these differences. A recent randomized controlled study on 100 patients (50 were taught Rajayoga and practiced 20 minutes per day for 6 weeks, the other 50 did not practice any meditation; all patients received standard treatment), found that while both groups benefited from the medication, the percentage of relief experienced was much higher in the intervention group, as noted from the Hamilton Anxiety and Depression scales (Kiran, Arora, \& Girgila, 2014). This indicates that novices (with less experience than STP) can also benefit from negative affect reduction through Rajayoga practice.

Surprisingly, the groups in the present sample showed no LS related differences (even though the means were higher for the practitioners and the Kruskal-Wallis test did cross the significance threshold), unlike a previous study which showed enhanced "self-satisfaction" among Rajayoga practitioners as compared to controls (Ramesh et al., 2013). The previous study did not examine LS using the "gold standard" (Diener et al., 1985) but instead, they used a subset of questions from the Oxford Happiness Questionnaire (Hills \& Argyle, 2002), an instrument that has received criticism for not being directly relevant to assessment of SWB (Kashdan, 2004). Closer examination revealed that LTP and STP show enhanced LS as compared to the population score (Agrawal et al., 2011) reported in the literature $(p<0.05$ and $p$ $<0.01$ respectively). Thus, while it is possible that the Rajayoga practitioners have slightly enhanced LS as compared to ZTP, the effect size is still quite small and can be ignored in order to make a conservative estimate. An alternative explanation could be that while LTP and STP do show significant enhancements in other aspects of wellbeing, their goals for self- 
development and spiritual-transcendence may also be much higher, thereby contributing to an average level of LS similar to ZTP. Since LS is a cognitive-evaluative measure of SWB (unlike PA and NA which contribute to affect balance), the comparison to higher goals might offset the gains in satisfaction achieved due to higher levels of PA and reduced levels of NA. Finally, the Jonckheere-Terpstra test revealed a statistically significant trend of increased LS with duration of practice. (Note that the results show a decreasing trend with decreasing duration of practice - the result is equivalent.)

\subsubsection{Psychological wellbeing}

There are no studies that have examined psychological wellbeing (PWB) for the adult Indian population for the age range used in the present study. However, there is one report of a large field trial (Mehrotra, Tripathi, \& Banu, 2013) for Indian youth (age range 20-35 years, $n=614$ ) which can be used as a starting point for examining the results. There were no significant differences (all $p>0.05$ ) between the scores obtained by ZTP and the youth population for PWB (overall) or for any of the subscales Self-Acceptance (SA), Mastery and Competence (MC), Positive Relations (PR), and Engagement and Growth (EG). Thus, the results from the current study replicate the findings from the youth study and extend and generalize the results to the adult urban Indian population.

LTP and STP had significantly higher overall PWB scores than ZTP. For MC, only LTP showed significantly enhanced scores as compared to ZTP, which indicates that long-term practice does confer additional wellbeing benefits as compared to short-term practice. Additionally, a statistically significant trend of increasing SA, PR and EG was found with increased years of practice. It is worth noting that PR and EG are considered to be key contributors to flourishing in Seligman's "PERMA" model of wellbeing (Seligman, 2012). Thus, higher proficiency of practice sustained over a long term of practice may well be the key to a life of flourishing.

It is fruitful to discuss the non-significant differences in LS and SA. Global satisfaction with life was not enhanced, possibly due to a sustained gap between enhanced wellbeing and enhanced goals, as it is known that LS measures have an implicit comparison with have-want discrepancy $(\mathrm{Wu}, 2008)$. Another factor to be considered is that the study did not assess participants' personal ideals and goals which could possibly influence the LS ratings. SA is defined as having a positive attitude towards the self and a positive view of past life, while acknowledging and accepting one's good and bad qualities (Ryff, 1989). A similar and more recent perspective considers SA to be an overall sense of contentment with oneself and with the way one's life has played out (Mehrotra et al., 2013). While introspection and self-evaluation are important tools for a meditator, self-criticism and judgmental non-acceptance are not healthy - they are strongly linked to various forms of psychopathology such as depression, anxiety, substance abuse, suicide (Kannan \& Levitt, 2013). SA on the other hand, is related to self-compassion, which implies being kind to oneself in the face of pain and failure in a mindful way, in a manner distinct from self-pity, self-centeredness and self-complacency (Barnard \& Curry, 2011). It is likely that in Rajayoga, a path directed towards self-mastery, critical selfevaluation and self-compassion balance out. Both LS and SA did show a significant trend of enhancement with duration of practice, which indicates that the LS and SA are slightly higher in the practitioners.

An enhancement in sense of mastery (especially self-mastery, since it is a key goal for Rajayoga) in LTP is not surprising. It is noteworthy that the mean values for MC in STP are higher than LTP too, but the SD is smaller and it just missed statistical significance. The trend 
test was significant, showing that STP also have enhanced sense of mastery as compared to ZTP. Rajayoga mastery requires significant lifestyle changes, which may pose adjustment challenges in PR, as the practitioner tries to bring about these changes while engaging with the circles of family, friends and colleagues. With time, these relationships take a more positive turn, as evidenced by the significant increased trend.

\subsubsection{Meaning in life}

The Life Regard Index (LRI) evaluates the framework (FR) through which an individual views life goals and aspirations that make life meaningful, and fulfillment (FU) of these goals and aspirations. This scale can be suitably used for practitioners of different schools of thought, as it is not based on any particular belief system (Debats et al., 1993) i.e., it does not base meaning on any specific external belief system or philosophy. In the present study, both LTP and STP had a significantly enhanced sense of meaning in life as compared to ZTP. This is to be expected, as Rajayoga offers a consolidated knowledge framework (as one of the four subjects of Rajayoga) that can be used by the practitioner to look at life and its current challenges and an approach to create a potentially better future. Among the other subjects are meditation (which allows an experiential basis of connecting with God and other living beings), spiritual lifestyle (which brings about discipline and inculcation of desirable qualities), and, finally, service (which promotes contribution to the welfare of others). Through these subjects, Rajayoga provides a structure for developing meaning in life.

\subsubsection{Beliefs and quality of life}

The Spirituality, Religiousness and Personal Beliefs (SRPB) instrument was developed (WHOQOL SRPB Group, 2006) in conjunction with the Quality of Life assessment tool. It was validated across several religions and cultures (in 18 countries) and recognizes the contribution of the individual's belief system to quality of life. Both LTP and STP had significantly higher scores (than ZTP) for the overall SRPB scale, as well as the subscales measuring spiritual connection, meaning and purpose in life, wholeness and integration, inner peace, hope and optimism, and faith. There was also a significantly increased trend for experiences of awe and wonder, and for spiritual strength. Thus the contribution of the Rajayoga knowledge/belief system to the quality of life in the practitioners is substantial.

\subsubsection{Wellbeing, proficiency and duration of practice}

Rajayoga practice proficiency was correlated with almost all wellbeing outcomes, with the largest correlations for SRPB overall, wholeness, PA, peace, spiritual strength and PWB overall. These show the contribution of practice proficiency on enhanced wellbeing. As expected, progress in wellbeing was also correlated with a number of wellbeing outcomes. The largest correlations were for PA, SRPB overall, wholeness, faith, and PWB overall. This shows a limited extent of convergent validity of the scales. Progress in wellbeing does not necessarily imply higher wellbeing (if the baseline levels prior to Rajayoga practice were lower, for example) but they are likely to be similar. Years of Rajayoga practice were correlated with EG, wholeness and spiritual strength, showing that there are some aspects of wellbeing that benefit from increased years of practice.

Overall, the wellbeing measures indicate that even short-term Rajayoga practice confers benefits of enhancements in subjective wellbeing and psychological wellbeing, and provides a framework to meaningfully engage with life. Sustaining Rajayoga practice over time brings 
about additional benefits in terms of better engagement and growth, as well as enhanced spiritual strength and an overall sense of wholeness and integration between different aspects of inner and outer life.

\section{Overall Discussion}

Our findings suggest that BKRY practitioners experience a sense of progress across a number of dimensions in life. This progress in wellbeing is strongly associated with higher levels of proficiency in spiritual study, meditation experience, inculcation of virtues, and service orientation. While individual backgrounds (such as prior religiosity, supportive family etc.) may be of help to the practitioner, anyone who develops proficiency in practice is likely to experience progress in wellbeing.

There are several limitations of this study. Since these were cross-sectional studies, there was no opportunity to make causal inferences. A prospective study could also evaluate the relationship between personality factors and wellbeing by considering the individuals' personality prior to the initiation into BKRY and the changes that have been brought forth after initiation. Such an evaluation would indicate (i) whether there were any particular personality patterns noted in individuals who chose to embrace BKRY meditation, (ii) what kind of personality changes were likely due to practice of BKRY, and (iii) whether personality factors predict progress in wellbeing. However, carrying out such a longitudinal study to consider the effects of long-term practice (such as the LTP group) is not an easy undertaking. A related limitation is that we surveyed only current practitioners. Since we did not survey those who stopped BKRY practice, we cannot rule out any factors that might enable individuals to adapt to the BKRY lifestyle. Another limitation is due to the reliance on only self-report measures, which are vulnerable to reporting biases. A study that simultaneously evaluates physiological variables would be less susceptible to this bias.

Our study makes several contributions to the literature. To the best of our knowledge, this is the first comprehensive report that examines enhancement of wellbeing in practitioners of a school of thought in terms of their proficiency in spiritual lifestyle practices. We have found that proficiency of practice has much better correlation with different facets of wellbeing than duration of practice. We believe that studying different schools of thought and their practices can help unravel different pathways adopted by individuals for enhancement of wellbeing. We recommend that future studies in various schools of spiritual/religious practice incorporate tradition-specific proficiency assessment and suggest that the Progress in Wellbeing scale can be easily adapted for assessing practice-aided improvements in wellbeing.

\section{Authors}

Ajay Kumar Nair

National Institute of Mental Health and Neuro Sciences (NIMHANS), India

John P. John

National Institute of Mental Health and Neuro Sciences (NIMHANS), India

Seema Mehrotra

National Institute of Mental Health and Neuro Sciences (NIMHANS), India

Bindu M. Kutty

National Institute of Mental Health and Neuro Sciences (NIMHANS), India

bindu.nimhans@gmail.com 


\section{Publishing Timeline}

Received 23 November 2017

Accepted 30 July 2018

Published 9 December 2018

\section{References}

Agrawal, J., Murthy, P., Philip, M., Mehrotra, S., Thennarasu, K., John, J. P., . . Isaac, M. (2011). Sociodemographic correlates of subjective well-being in urban India. Social Indicators Research, 101(3), 419434. https://doi.org/10.1007/s11205-010-9669-5

Awasthi, B. (2013). Issues and perspectives in meditation research: In search for a definition. Frontiers in Psychology, 3, 1-9. https://doi.org/10.3389/fpsyg.2012.00613

Barnard, L. K., \& Curry, J. F. (2011). Self-compassion: Conceptualizations, correlates, \& interventions. Review of General Psychology, 15(4), 289-303. https://doi.org/10.1037/a0025754

Battista, J., \& Almond, R. (1973). The development of meaning in life. Psychiatry, 36(4), 409-427. https://doi.org/10.1080/00332747.1973.11023774

Bharshankar, J. R., Mandape, A. D., Phatak, M. S., \& Bharshankar, R. N. (2015). Autonomic functions in Raja-yoga meditators. Indian Journal of Physiology and Pharmacology, 59(4), 396-401.

Brahma Kumaris. (2018). Brahma Kumaris. http://www.brahmakumaris.org/

Brefczynski-Lewis, J. A., Lutz, A., Schaefer, H. S., Levinson, D. B., \& Davidson, R. J. (2007). Neural correlates of attentional expertise in long-term meditation practitioners. PNAS, 104(27), 11483-11488. https://doi.org/10.1073/pnas.0606552104

Dahl, C. J., Lutz, A., \& Davidson, R. J. (2015). Reconstructing and deconstructing the self: Cognitive mechanisms in meditation practice. Trends in Cognitive Sciences, 19(9), 515-523. https://doi.org/10.1016/j.tics.2015.07.001

Davidson, R. J., \& Kaszniak, A. W. (2015). Conceptual and methodological issues in research on mindfulness and meditation. American Psychologist, 70(7), 581-592. https://doi.org/10.1037/a0039512

Debats, D. L., van der Lubbe, P. M., \& Wezeman, F. R. A. (1993). On the psychometric properties of the life regard index (LRI): A measure of meaningful life: An evaluation in three independent samples based on the Dutch version. Personality and Individual Differences, 14(2), 337-345. https://doi.org/10.1016/0191-8869(93)90132-M

Diener, E., Emmons, R. A., Larson, R. J., \& Griffin, S. (1985). The Satisfaction With Life Scale. Journal of Personality Assessment, 49(1), 71-75. https://doi.org/10.1207/s15327752jpa4901 13

Dunn, T. J., Baguley, T., \& Brunsden, V. (2014). From alpha to omega: A practical solution to the pervasive problem of internal consistency estimation. British Journal of Psychology, 105(3), 399-412. https://doi.org/10.1111/bjop.12046

Ericsson, K. A. (2006). The influence of experience and deliberate practice on the development of superior expert performance. In A. K. Ericsson, N. Charness, R. R. Hoffman, \& P. J. Feltovich (Eds.), The Cambridge handbook of expertise and expert performance (Vol. 38, pp. 685-705). New York, NY: Cambridge University Press.

Feldman Barrett, L., \& Russell, J. A. (1998). Independence and bipolarity in the structure of current affect. Journal of Personality and Social Psychology, 74(4), 967-984.

https://doi.org/10.1037/0022-3514.74.4.967

Goyal, M., Singh, S., Sibinga, E. M. S., Gould, N. F., Rowland-Seymour, A., Sharma, R., . . Haythornthwaite, J. A. (2014). Meditation programs for psychological stress and well-being: A systematic review and meta-analysis. JAMA Internal Medicine, 174(3), 357-368. https://doi.org/10.1001/jamainternmed.2013.13018

Gupta, S. K., Sawhney, R. C., Rai, L., Chavan, V. D., Dani, S., Arora, R. C., . . Nanda, N. C. (2011). Regression of coronary atherosclerosis through healthy lifestyle in coronary artery disease patients: Mount Abu Open Heart Trial. Indian Heart Journal, 63(5), 461-469. 
Hills, P., \& Argyle, M. (2002). The Oxford Happiness Questionnaire: A compact scale for the measurement of psychological well-being. Personality and Individual Differences, 33(7), 1073-1082. https://doi.org/10.1016/S0191-8869(01)00213-6

Hölzel, B., \& Ott, U. (2006). Relationships between meditation depth, absorption, meditation practice, and mindfulness: A latent variable approach. The Journal of Transpersonal Psychology, 38(2), 179-200.

Kaliman, P., Álvarez-López, M. J., Cosín-Tomás, M., Rosenkranz, M. A., Lutz, A., \& Davidson, R. J. (2014). Rapid changes in histone deacetylases and inflammatory gene expression in expert meditators. Psychoneuroendocrinology, 40, 96-107. https://doi.org/10.1016/j.psyneuen.2013.11.004

Kannan, D., \& Levitt, H. M. (2013). A review of client self-criticism in psychotherapy. Journal of Psychotherapy Integration, 23(2), 166-178. https://doi.org/10.1037/a0032355

Kashdan, T. B. (2004). The assessment of subjective well-being (issues raised by the Oxford Happiness Questionnaire). Personality and Individual Differences, 36(5), 1225-1232. https://doi.org/10.1016/S01918869(03)00213-7

Kiran, C. H., Arora, A. K., \& Girgila, K. K. (2014). Effect of short-term Rajyoga meditation on anxiety and depression. Pakistan Journal of Physiology, 10(1-2), 18-20.

Kiran, U., Behari, M., Venugopal, P., Vivekanandhan, S., \& Pandey, R. (2005). The effect of Autogenic Relaxation on chronic tension headache and in modulating cortisol response. Indian Journal of Anaesthesia, 49(6), 474-478.

Koenig, H. G. (2012). Religion, spirituality, and health: The research and clinical implications. ISRN Psychiatry, 2012, 278730. https://doi.org/10.5402/2012/278730

Lutz, A., Jha, A. P., Dunne, J. D., \& Saron, C. D. (2015). Investigating the phenomenological matrix of mindfulness-related practices from a neurocognitive perspective. American Psychologist, 70(7), 632658. https://doi.org/10.1037/a0039585

Lyubomirsky, S., \& Lepper, H. S. (1999). A measure of subjective happiness: Preliminary reliability and construct validation. Social Indicators Research, 46(2) 137-155. https://doi.org/10.1023/A:1006824100041

Mandape, A., Bharshankar, J., \& Phatak, M. (2015). Effect of Raja Yoga meditation on the lipid profile of healthy adults in Central India. Journal of Medical Sciences and Health, 1(1), 10-13.

Manocha, R., Black, D., \& Wilson, L. (2012). Quality of life and functional health status of long-term meditators. Evidence-Based Complementary and Alternative Medicine, 2012, 350674. https://doi.org/10.1155/2012/350674

Mehrotra, S., Tripathi, R., \& Banu, H. (2013). Psychological well-being: Reflections on an elusive construct and its assessment. Journal of the Indian Academy of Applied Psychology, 39(2), 189-195.

Misra, N., Gupta, A., Alreja, S., \& Prakash, O. (2013). Effect of Raj Yoga meditation on affective \& cognitive functions. International Journal of Heath Sciences and Research, 3(2), 38-46.

Nair, A. K., Sasidharan, A., John, J. P., Mehrotra, S., \& Kutty, B. M. (2017). Just a minute meditation: Rapid voluntary conscious state shifts in long term meditators. Consciousness and Cognition, 53, 176184. https://doi.org/10.1016/j.concog.2017.06.002

Orme-Johnson, D. W., \& Dillbeck, M. C. (2014). Methodological concerns for meta-analyses of meditation: Comment on Sedlmeier et al. (2012). Psychological Bulletin, 140(2), 610-616. https://doi.org/10.1037/a0035074

Panda, R., Bharath, R. D., Upadhyay, N., \& Mangalore, S. (2016). Temporal dynamics of the default mode network characterize meditation-induced alterations in consciousness. Frontiers in Human Neuroscience, 10, 1-12. https://doi.org/10.3389/fnhum.2016.00372

Ramesh, M. G., Sathian, B., Sinu, E., \& Kiranmai, S. R. (2013). Efficacy of Rajayoga meditation on positive thinking: An index for self-satisfaction and happiness in life. Journal of Clinical and Diagnostic Research, 7(10), 2265-2267. https://doi.org/10.7860/JCDR/2013/5889.3488

Ramsay, T., Manderson, L., \& Smith, W. (2010). Changing a mountain into a mustard seed: Spiritual practices and responses to disaster among New York Brahma Kumaris. Journal of Contemporary Religion, 25(1), 89-105. https://doi.org/10.1080/13537900903416838

Rao, D., \& Mehrotra, S. (2006). Negotiation of life-tasks and subjective well-being in young adults pursuing professional courses. Psychological Studies, Special issue: Psychology of health and well-being, 51(2-3), 144-152. 
Ryff, C. D. (1989). Happiness is everything, or is it ? Explorations on the meaning of psychological wellbeing. Journal of Personality and Social Psychology, 57(6), 1069-1081. https://doi.org/10.1037/0022$\underline{3514.57 .6 .1069}$

Ryff, C. D., \& Keyes, C. L. M. (1995). The structure of psychological well-being revisited. Journal of Personality and Social Psychology, 69(4), 719-727. http://dx.doi.org/10.1037/0022-3514.69.4.719

Sedlmeier, P., Eberth, J., Schwarz, M., Zimmermann, D., Haarig, F., Jaeger, S., \& Kunze, S. (2012). The psychological effects of meditation: A meta-analysis. Psychological Bulletin, 138(6), 1139-1171. https://doi.org/10.1037/a0028168

Seligman, M. E. P. (2012). Flourish: A visionary new understanding of happiness and well-being. New York, NY: Simon and Schuster.

Sharma, R. (2006). Meditation and mental well being. Indian Journal of Physiology and Pharmacology, 50(3), 205-214.

SpARC. (2018). Spiritual Applications Research Centre. http://bksparc.in/sparc wing.html

Telles, S., \& Desiraju, T. (1993). Autonomic changes in Brahmakumaris Raja yoga meditation. International Journal of Psychophysiology, 15(2), 147-152. https://doi.org/10.1016/0167-8760(93)90072-W

Telles, S., \& Naveen, K. V. (2004). Changes in middle latency auditory evoked potentials during meditation. Psychological Reports, 94(2), 398-400. https://doi.org/10.2466/pr0.94.2.398-400

Thomas, J. W., \& Cohen, M. (2014). A methodological review of meditation research. Frontiers in Psychiatry, 5, 74. https://doi.org/10.3389/fpsyt.2014.00074

Vyas, R., \& Dikshit, N. (2002). Effect of meditation on respiratory system, cardiovascular system and lipid profile. Indian Journal of Physiology and Pharmacology, 46(4), 487-491.

Watson, D., Clark, L. A., \& Tellegen, A. (1988). Development and validation of brief measures of positive and negative affect: The PANAS scales. Journal of Personality and Social Psychology, 54(6), 1063-1070. https://doi.org/10.1037/0022-3514.54.6.1063

WHOQOL SRPB Group. (2006). A cross-cultural study of spirituality, religion, and personal beliefs as components of quality of life. Social Science \& Medicine, 62(6), 1486-1497. https://doi.org/10.1016/j.socscimed.2005.08.001

Wiist, W. H., Sullivan, B. M., St. George, D. M., \& Wayment, H. A. (2012). Buddhists' religious and health practices. Journal of Religion and Health, 51(1), 132-147. https://doi.org/10.1007/s10943-010-9348-5

$\mathrm{Wu}$, C.-H. (2008). The role of perceived discrepancy in satisfaction evaluation. Social Indicators Research, 88(3), 423-436. https://doi.org/10.1007/s11205-007-9200-9 